\title{
Choice of sleeping position for infants: possible association with cot death
}

\author{
A C Engelberts, G A de Jonge
}

The sleeping position of infants may seem a trivial aspect of baby care. Because of a possible association with cot death, however, it deserves serious consideration. Different positions have been strongly advocated and it seems that opinions differ widely among countries and change over time. In contrast to the strong opinions is the paucity of research and published reports on the actual benefits and possible dangers of the various sleeping positions. We therefore reviewed the available data about the sleeping position to try and give an answer to perhaps one of the most elementary questions of baby care: how do I place my baby in its cot?

\section{Sleeping positions}

There are four more or less stable positions in which an infant can sleep: supine, on its side, prone with the face turned to one side, or prone face down. Obviously infants are rarely placed face down with their noses on their mattresses, although some parents may eventually do so after repeatedly finding their infant in such a position. The sleeping position is determined by several factors: the position in which an infant is placed, the motor abilities that are developing with the age of the child, and the clothing and bedclothes that may restrict movement; the child's movements are also influenced by various factors such as dyspnoea and illness.

The development of an infant's ability to turn has been widely studied, although almost exclusively when awake, and not when the infant is presumably asleep. Hassall and Vandenberg, however, surveyed the positions in which more than 4000 babies in New Zealand from 1 to 4.5 months of age were usually placed, and those in which they were later found. ${ }^{1}$ The side position was the least stable, with $47 \%$ of the 1 month old babies placed on their sides being found in a different position. As the age of the infants increased, parents more often placed them in the more stable prone or supine position, probably because babies do not stay on their sides for long. Even in the prone and supine positions $14 \%$ and $10 \%$ of infants up to 4.5 months of age, respectively, changed position, and as many as $3 \%$ of the 1 month old infants who were placed prone managed to end up on their backs.

In a survey that we conducted in the summer of 1988, parents of 406 infants aged from 2 weeks to 8 months were asked at 'well baby' clinics how they had put their infants to bed the night before, and in which position the infants were found that morning. Of the 227 infants not yet 4 months old, 123 (54\%) had been placed laterally. Only 37 of these laterally placed infants $(30 \%)$, however, were still on their sides the next morning: $80(65 \%)$ had turned to supine, five (4\%), had turned to prone, and in one $(1 \%)$ the position was unknown. In the same age group 38 infants were placed prone (17\%): none turned to another position. Of the 66 infants placed supine (29\%) only two turned (3\%): all were 3 months old and all ended up prone. In the age group 4 months and over there were 179 infants. The lateral position was even less stable than in the younger age group: of the 16 infants placed on their sides, 13 were found supine, and in three the position was unknown. In this older group 137 infants (77\%) were placed supine of whom $118(86 \%)$ remained supine; 26 infants $(15 \%)$ were placed prone of whom $21(81 \%)$ were found still prone the next morning.

\section{Benefits and disadvantages of various sleeping positions}

In 1960 the English paediatrician Holt wrote that it was common practice in the United States to place babies prone, while he could not recall an English mother doing so. ${ }^{2}$ The most common reasons given by the American mothers were that the infant was more comfortable and that it was safer in case of vomiting-arguments that are often heard today. Holt described the arguments as 'interesting' but doubted that they would 'stand critical scrutiny', probably influenced by his experience that the English babies placed supine fared quite well. Although doctors have changed their opinions about the best sleeping position for babies from time to time and place to place, it is curious that the actual benefits and disadvantages have received so little 'critical scrutiny'. The following considerations have been put forward:

(1) The most thoroughly researched reason for placing an infant prone is to prevent gastrooesophageal reflux. The prone, and in particular the prone position with the head raised, has conclusively been shown to significantly reduce the amount of reflux in symptomatic and asymptomatic infants. ${ }^{3-7}$ Gastro-oesophageal reflux in asymptomatic infants, however, seems to occur mainly in the first two postprandial hours and rarely during sleep. ${ }^{8} 9$ In Western countries it is often thought that infants who sleep supine are also at greater risk of vomiting

Correspondence to:

Dr Engelberts. 
and aspiration, although this has not been established. ${ }^{10}$

(2) Research has also been carried out into the association between the position of an infant and his or her pulmonary function, and various advantages of a prone position have been postulated. ${ }^{11-18}$ Two reports have mentioned the energy expenditure in various positions, with contradictory results. ${ }^{16} 17$ There has been no study to our knowledge concerning the possible long term effects of a prone or a supine position. The influence of body position on the pulmonary function of infants is still unclear and further studies are required; furthermore, it does not seem wise to extrapolate findings from studies of preterm infants to infants born at full term. For preterm infants, however, sleeping prone may be advantageous during the neonatal period; a recent editorial in the Lancet suggests weighing individual considerations and adopting an empirical approach. ${ }^{18}$

(3) Placing an infant prone can have certain orthopaedic advantages. The prone position might prevent infantile scoliosis, although this is not certain. ${ }^{19-21}$ Lying prone can probably prevent limitation of hip abduction; this seems to be induced by a habitual semilateral supine position on the same side and needs no treatment except to encourage another position. Subsequently the hip joint will develop normally. Sleeping prone has no preventive effect on the more serious congenital dislocation of the hip. ${ }^{22}$ Placing an infant prone, especially in the kneechest position, may cause tiptoe walking and a turning in or turning out of the feet. These faulty alignments of the feet and legs usually correct themselves when the child starts to walk. $^{23} 24$ Furthermore, a habitual lateral or supine position may cause moulding of the skull.

(4) Placing an infant prone has been considered advantageous for the motor and even psychological development of a child. ${ }^{25}$ Holt is, however, one of the few who actually carried out a study into this aspect of motor development. It seems that in children who habitually lie prone, the extensor phase of motor development is more advanced than the flexor phase, and these infants crawl and stand one to several months earlier than infants who lay supine, and start sitting at the same time as they start crawling. Infants who are usually supine have better head control and sit up earlier, and start sitting some time before they start crawling. Even if one agrees that the prone motor development is preferable, it is likely that these considerations apply to the position in which a child is placed when awake and active, not when asleep.

As for the psychological development of infants, to our knowledge there have been two controlled studies on the psychological effects of positioning. ${ }^{26}{ }^{27}$ Brackbill et al studied 30 infants for two hours: prone infants slept more, cried less, and moved less. ${ }^{26}$ Keitel et al placed each newborn infant admitted to their nursery either prone or supine in rotation. ${ }^{27}$ After a four day period they found that the supine infants had more nappy rashes and self inflicted scratches, and cried twice as much as the prone babies.
(5) Infants suffering from the Pierre Robin syndrome should be nursed prone because they develop 'pseudo' macroglossia as a result of the abnormal anchorage of the tongue and the reduced buccal cavity. Under the influence of gravity the tongue can obstruct the oropharynx when these infants are placed supine. ${ }^{28}$

(6) A common argument in favour of placing an infant prone is to soothe 'three months colic'. Illingworth described in 1954 that placing an infant prone usually brings some relief. ${ }^{29}$ Although this has often been mentioned since, we know of no controlled study. Perhaps the same mechanism is responsible as described by Keitel et al in their group of infants who presumably did not have colic-namely that over half of the infants stopped crying when placed on their stomachs whereas infants who cried while lying prone only occasionally stopped when placed supine. ${ }^{27}$

The possibility of an association between cot death and the position in which an infant has been placed for sleep deserves serious consideration. This is not a subject that lends itself easily to prospective trials, both because of the low incidence of cot death (which would entail enrolling thousands of infants), and because of the nature of cot death itself. Several epidemiological studies have been conducted, however, and research has been carried out into the possible mechanisms that could explain such an association. There has also been some work into the correlation between trends in sleeping position and trends in the incidence of cot death. The following body of evidence links cot death to the prone sleeping position.

\section{Association between sleeping position and cot} death

The earliest epidemiological studies did not show a clear association between cot death and the infant's sleeping position. Carpenter and Shaddick reported that affected infants were found face downward more often than was to be expected from their usual sleeping habits or those of controls; the association was not significant, however, after discriminant analysis. ${ }^{30}$ Froggatt's classic epidemiological study did not show a significant association between sleeping prone and cot death. ${ }^{31}$ The prevalence of this sleeping position was very low however, both in the series of index cases (7\%) and in the series of reference cases (4\%); sleeping supine, on the other hand, did occur significantly less in his group of cot deaths. Bergman et al reported in their study from King County, Washington, USA, that the distribution of sleeping positions (among cot deaths) was 'typical of infants in general in our community', but gave no details on how the information was obtained. ${ }^{32}$

Recent reports have suggested that a renewed appraisal is necessary. Kahn et al found a significant difference in sleeping position between babies dying of the sudden infant death syndrome (SIDS) and 'near miss' children; they did not, however, find a difference between SIDS infants and their controls. ${ }^{33}$ This study included both Belgian and French infants, and 
Studies that mentioned the sleeping position of infants that died of SIDS

\begin{tabular}{|c|c|c|c|c|c|c|}
\hline \multirow[t]{2}{*}{ Author } & \multirow[t]{2}{*}{ Country and dates } & \multicolumn{2}{|c|}{ Infants that died of SIDS } & \multicolumn{2}{|c|}{ Reference group } & \multirow{2}{*}{$\begin{array}{l}\text { Statistical } \\
\text { testing }\end{array}$} \\
\hline & & $\begin{array}{l}\text { Total } \\
\text { No }\end{array}$ & $\begin{array}{l}\text { Sleeping } \\
\text { position }\end{array}$ & $\begin{array}{l}\text { Total } \\
\text { No }\end{array}$ & $\begin{array}{l}\text { Sleeping } \\
\text { position }\end{array}$ & \\
\hline Carpenter and Shaddick ${ }^{30}$ & England $1958-61$ & 82 & $\begin{array}{l}\text { 'found face down } \\
\text { rather more' }\end{array}$ & 146 & Not stated & 'Not significant' \\
\hline $\begin{array}{l}\text { Froggatt }^{31} \\
\text { Bergman } \text { et } a l^{32}\end{array}$ & $\begin{array}{l}\text { Northern Ireland } 1965-7 \\
\text { King County, Washington, } \\
\text { USA 1965-8 }\end{array}$ & $\begin{array}{l}148 \\
170\end{array}$ & $\begin{array}{l}7 \% \text { Usually prone } \\
50 \% \text { Found prone }\end{array}$ & $\begin{array}{l}148 \\
\text { Not } \\
\text { stated }\end{array}$ & $\begin{array}{l}\text { 4\% Usually prone } \\
\text { 'Similar percentage } \\
\text { prone' }\end{array}$ & $\begin{array}{l}\text { 'Not significant' } \\
\text { Not stated }\end{array}$ \\
\hline $\begin{array}{l}\text { Nicholl and O'Cathain } \\
\text { Kahn et } a l^{33}\end{array}$ & $\begin{array}{l}\text { United Kingdom 1976-9 } \\
\text { Belgium and France } \\
1977-82\end{array}$ & $\begin{array}{r}265 \\
73\end{array}$ & $\begin{array}{l}42 \% \text { Usually prone } \\
71 \% \text { Usually prone }\end{array}$ & $\begin{array}{l}273 \\
177\end{array}$ & $\begin{array}{l}25 \% \text { Usually prone } \\
68 \% \text { Usually prone }\end{array}$ & $\begin{array}{l}\text { Relative risk } 2 \cdot 2 \\
\text { 'Not significant' }\end{array}$ \\
\hline $\begin{array}{l}\text { Saternus }{ }^{37} \\
\text { Beal }^{34} \\
\text { Tonkin }^{38}\end{array}$ & $\begin{array}{l}\text { Cologne, Germany 1974-84 } \\
\text { Adelaide, Australia 1970-84 } \\
\text { Auckland, New Zealand } \\
1972,1973 \text {, and } 1981\end{array}$ & $\begin{array}{r}75 \\
133 \\
91\end{array}$ & $\begin{array}{l}81 \% \text { Found prone } \\
8 \% \text { Placed supine } \\
56 \% \text { Found prone }\end{array}$ & $\begin{array}{r}306 \\
152 \\
1882\end{array}$ & $\begin{array}{l}40 \% \text { Usually prone } \\
23 \% \text { Placed supine } \\
29 \cdot 5 \% \text { Usually prone }\end{array}$ & $\begin{array}{l}\mathrm{p}<0.01 \\
\text { Not stated } \\
\text { 'Not significant' }\end{array}$ \\
\hline Cameron et $a l^{39}$ & $\begin{array}{l}\text { Melbourne, Australia } \\
1980-2\end{array}$ & 208 & 69\% Prone & 393 & $41 \%$ Usually prone & $\mathrm{p}<0.001$ \\
\hline de Jonge et $a l^{40}$ & The Netherlands $1980-6$ & 142 & $85 \%$ Placed prone & 320 & $62 \%$ Usually prone & $\begin{array}{l}\mathrm{p}<0.0001 \\
\text { Relative risk } 3.2\end{array}$ \\
\hline $\begin{array}{l}\text { Sénécal } e t a l^{41} \\
\text { Lee } e t ~ a l^{42}\end{array}$ & $\begin{array}{l}\text { Rennes, France } 1984 \\
\text { Hong Kong 1986-7 }\end{array}$ & $\begin{array}{l}20 \\
16\end{array}$ & $\begin{array}{l}85 \% \text { Placed prone } \\
44 \% \text { Usually prone }\end{array}$ & $\begin{array}{r}318 \\
32\end{array}$ & $\begin{array}{l}30 \cdot 5 \% \text { Usually prone } \\
6 \% \text { Usually prone }\end{array}$ & $\begin{array}{l}\mathrm{p}<0.001 \\
\mathrm{p}<0.01, \text { odds } \\
\text { ratio } 11.67\end{array}$ \\
\hline McGlashan $^{43}$ & Tasmania $1980-6$ & 164 & $58.5 \%$ Usually prone & 329 & $42 \cdot 9$ Usually prone & $\mathrm{p}<0.001$ \\
\hline
\end{tabular}

this might have confounded the comparison of sleeping positions, as it is difficult to assess the influence of local traditions. Beal ${ }^{34}$ and Davies ${ }^{35}$ compared the incidence of SIDS in various countries and found lower incidences in communities that usually place their infants supine. A review of case-control studies of SIDS that mention sleeping position is given in the table. With the exception of the study of Bergman et al the studies showed that the prone sleeping position was more common among cot deaths, although this trend was not always statistically significant. Studies did not often specify whether the habitual sleeping position, the position in which the infants were last placed, or the position in which the infants were found was studied, which makes comparisons difficult. Furthermore, while it is necessary to take into account local traditions and the age of the infants when choosing a reference group, it is unclear if this was always considered.

\section{Hypotheses concerning sleeping position and cot death}

Though it seems clear that there is an association between sleeping prone and cot death it is difficult to prove a causal relationship. If there is a mechanism by which one can envisage such an association this would make causality more plausible. If a prone sleeping position is a causative factor in cot death, it obviously does not cause a cot death on its own and it is not a factor in all cot deaths, but it might be a preventable aspect of the complicated sequence of events leading to a cot death. Several hypotheses have been published that offer possible explanations.

Tonkin proposed that cot death could be caused by occlusion of the infant's airway at its vulnerable oropharyngeal level. ${ }^{44}$ She stated that there were certain factors that could cause this occlusion, such as the mandible and tongue being pressed backwards by the weight of the infant's own head on the mattress. This posterior movement of the jaw is possible because of the shallowness of the temporomandibular joint in infancy, and is facilitated by the low muscle tone during sleep. When the mandible is pressed backwards the tongue moves with it, and can obstruct the oropharyngeal airway behind the soft palate. Several studies have been published that support this hypothesis. ${ }^{45-47}$ Cross and Lewis found that pushing the jaw backwards or raising the floor of the mouth could cause respiratory obstruction, while not disturbing the infants sleep. ${ }^{45}$ Orr et al, however, found no significant difference in the occurrence or duration of central or obstructive apnoeic events whether the baby was in the prone, supine, or lateral position. ${ }^{48}$

Harding stated that the cartilage of an infant's nose is more compliant than that of an adults and could be more easily deformed by the weight of the infant's own head when lying prone. ${ }^{49}$ Tonkin and Partridge suggested that even incomplete obstruction of the nose could cause complete respiratory obstruction. ${ }^{50}$ If the diameter of the nasal passage is lessened-for example, by infection or external obstructionthe air flow must be increased. The faster the flow the greater the drop in pressure during inspiration, which could conceivably lead to collapse of the soft unsupported part of the respiratory tract, namely the oropharynx. Emery and Thorton noted an increase in the resistance to airflow in infants lying nose down. ${ }^{51}$ Although a substantial proportion of babies are able to switch to mouth breathing in case of nasal obstruction, ${ }^{49}$ there is also a group of infants who fail to do $\mathrm{so}^{4952}$ and the ability seems to diminish in the first few months of life. At an age of 5-6 months, however, the mouth breathing reflex is established in most children. ${ }^{52}$ Emery and Thorton also investigated the degree of obstruction to airflow by various external factors in a baby's cot such as mattresses, pillows, and their coverings; perhaps a small part of the association between the occurrence of cot death and lying prone must be put down to these factors. ${ }^{51}$

A different hypothesis concerns the circulation in the large vessels in the neck of infants. Gilles et al suggested that there might be a correlation between extreme head extension and SIDS. ${ }^{53}$ When dissecting the atlanto-occipital regions of infants who died of SIDS they often found a disproportion between the size of the posterior 
arch of the atlas and the size of the foramen magnum. As the head was brought to the end of extension on the atlas, the posterior arch could invert through the foramen magnum to such an extent that direct pressure was brought to bear on the medulla, and the vertebral arteries were compressed. They proposed that this mechanism could lead to repeated episodes of hypoxia thus causing the morphological changes of chronic hypoxia found in SIDS. Saternus et al carried out flow measurements in the large neck vessels at necropsy to try to demonstrate position dependent cerebral hypoxia. ${ }^{54}$ The combination of flexion/extension with rotation caused a large decrease in flow with repeated stoppages, particularly in the vertebral arteries. The authors recommended abandonment of the prone sleeping position, in which the head and neck of an infant often assumes these angles, and expressed a preference for a lateral positioning of infants. This hypothesis is not supported by a recent study of Lawson et al in which the cerebral oxidative metabolism was assessed in vivo by means of ${ }^{31} \mathrm{P}$ nuclear magnetic resonance spectroscopy and no change was found after a change in head position. ${ }^{55}$

The most recent hypothesis that takes into account the association between a prone position and cot death is that of Nelson et al. ${ }^{56}$ They postulated that a combination of several cultural infant care practices could cause hyperthermia. For example, the combination of excessive wrapping and clothing, combined with a raised metabolic rate as a result of mild infection, together with a prone position that reduces heat loss and enables caudal mobility under bedding, could lead to hyperthermia.

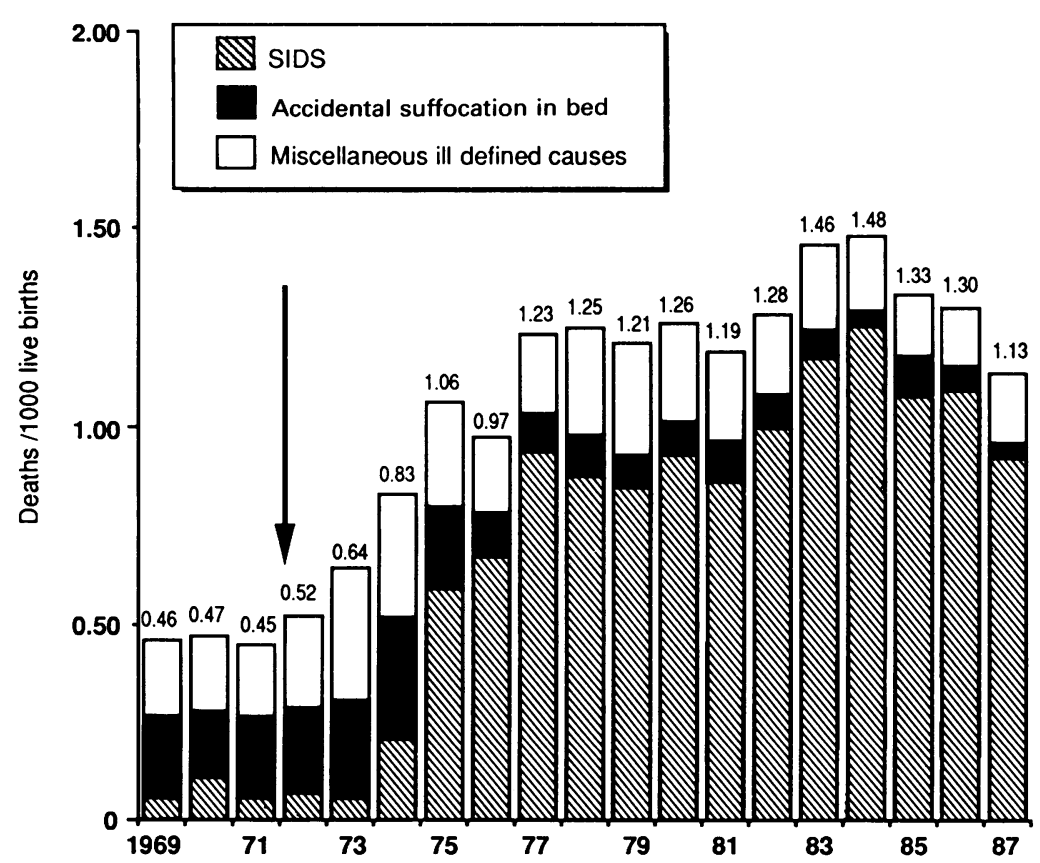

Deaths from SIDS and associated causes during the first year of life/1000 live births in The Netherlands 1969-87. $\mathbb{N}$ : Sudden death (cause unknown), cot death, SIDS; 1969-78 International Classification of Diseases (ICD) No 795.0, 1979-86 ICD No 798.0. : Accidential mechanical suffocation in bed or cradle; 1969-87 ICD No E913.0. $\square$ : Miscellaneous ill defined causes; 1969-78 ICD No 796. 0/796.2/796.3/796.9/E913.9, 1979-87 ICD No 798.9/799.0/799.9/E913.8/E913.9. The arrow indicates the time introduction of the prone sleeping position in The Netherlands.
Although the mechanism by which a prone position might contribute to a cot death is not immediately clear, the above hypotheses do give biological plausibility to the association. The oropharynx is the vulnerable part of the upper respiratory tract in infants, and obstructive apnoeas often occur there. ${ }^{57}$ We believe, therefore, that the hypotheses concerning the way in which lying prone could facilitate obstruction at this site, by either backward pressure on the mandible or partial external or nasal obstruction, merit special attention.

Trends in fashions of sleeping position and incidence of cot death

Although following two trends in time can never prove the causality of an association, a correlation between trends can give strong supportive evidence. This is the next step after comparing incidences between different countries, as Beal and Davies have done, because at least some important cultural differences are controlled for in this manner.

It used to be customary for Dutch infants to be placed on their sides or their backs when being put to bed. This changed, however, after the presentation of Reisetbauer and Czermack at the 13th International Paediatric Congress in Vienna in 1971, and their publications on this topic. ${ }^{25}$ Their arguments in favour of the prone position convinced many Dutch paediatricians, and this position became fashionable, with both the Dutch medical ${ }^{58}$ and popular press advising the prone position as the most healthy one for newborn and older infants in 1972. In this way, prone became the most common sleeping position for babies in The Netherlands. Regrettably such trends are rarely well documented: the only available reference is Swaak who stated that in $1982,52 \%$ of 1 month old babies in the province of Noord Brabant at least occasionally slept in a prone position. ${ }^{59}$

The registered incidence of cot death and its related causes has increased dramatically in The Netherlands over the last 15 to 20 years (figure). Whereas in 1969/71 cot death accounted for 0.46 deaths $/ 1000$ live births, the registered incidence was $1 \cdot 3 / 1000$ live births in 1986 , with a postperinatal mortality of 3.8 and a total infant mortality of $7 \cdot 8 / 1000$. Both changes in coding (in January 1979 the eighth revision of the International Classification of Diseases (ICD) was replaced by the ninth), and changes in certification as a result of greater familiarity of physicians with cot death, make it difficult to draw conclusions regarding a possible increase. Baak and Huber, however, concluded at the time that the low incidence in The Netherlands in 1969-71 was probably real; even if $10 \%$ of all other probable categories of infant death were undiagnosed SIDS, the incidence would not have been more than $0.53 / 1000 .^{60}$ Even if one takes an extremely exaggerated estimate and considers $40 \%$ of all deaths in these categories under which SIDS could conceivably be hidden (for example, infective diseases, or diseases of the respiratory or digestive tract) to be SIDS, the incidence would then have been $0 \cdot 84 / 1000$ : still much lower than the present Dutch inci- 
dence. Consequently, the Dutch rise in SIDS cannot be explained by certification errors alone. The increased neonatal survival of premature babies, a group at higher risk of cot death, can account for at the most $5 \%$ of the impressive rise. Another well known risk factor, maternal smoking, decreased rather than increased during this period.

The incidence of SIDS has also risen in Sweden, ${ }^{61} 62$ as well as in other Scandinavian countries. ${ }^{63} 64$ These countries are similar to The Netherlands in that they all had low infant mortality and all had a low incidence of cot death. Analysis of the trend in SIDS in Scandinavia is, however, more reliable because of the higher necropsy rates. The Swedish incidence increased from $0.48 / 1000$ live births in $1976^{61}$ to 0.94 in $1984-6 .^{62}$ The traditional sleeping position has also changed in Sweden since 1976, from supine to prone, although there is also reason to be unsure whether or not the trends are related. ${ }^{65}$ We have no information about changes in sleeping position in the other Scandinavian countries.

Recently a paper by Beal attracted considerable attention in South Australia. ${ }^{34}$ Preliminary results showed that both the prevalence of the prone sleeping position and the incidence of cot death has decreased there. ${ }^{66}$ In The Netherlands there was also considerable attention in the press in late 1987 after a lecture held by one of us on the association between cot death and sleeping prone. To gain insight into how care givers react to such adverse publicity two studies were conducted: one among parents of infants born before the publicity and one among parents of infants born in 1988. ${ }^{67} 68$ The publicity seems to have had a great influence on the way parents place their infants for sleep. In the first study $46 \%$ of the 659 infants studied always slept prone, and $10 \%$ sometimes slept prone before the publicity. Although parents attempted to 'wean' these children from sleeping prone they were not often successful. In the second study of 1763 children born after the publicity only $19 \%$ always slept prone and $8 \%$ sometimes slept prone. This change in the sleeping position policies of Dutch parents has been well documented. The first Dutch mortality figures indicate a $40 \%$ decrease in cot death in 1988 compared with $1987 .{ }^{69}$ This would support the hypothesis that sleeping prone can contribute to the occurrence of cot death.

The data in the histogram are reported by kind permission of the Central Bureau of Statistics, Voorburg, The Netherlands.

1 Hassall IB, Vandenberg $M$. Infant sleep position: a New Zealand survey. NZ Med $\mathcal{f}$ 1985;98:97-9.

2 Holt KS. Early motor development, posturally induced variations. F Pediatr 1960;57:571-5.

3 Vandenplas Y, Sacré L. Seventeen hour continuous esophageal pH monitoring in the newborn: evaluation of the influence of position in asymptomatic and symptomatic babies. F Pediatr Gastroenterol Nutr 1985;4:356-61.

4 Blumenthal I, Lealman GT. Effect of posture on gastroesophageal reflux in the newborn. Arch Dis Child 1982;57: 555-6.

5 Orenstein SR, Whitington PF. Positioning for prevention of gastroesophageal reflux. $\mathcal{f}$ Pediatr 1983;103:534-7.

6 Meyers WF, Herbst JJ. Effectiveness of positioning therapy for gastroesophageal reflux. Pediatrics 1982;69:768-72.

7 Vandenplas Y, Sacré-Smit L. Gastroesophageal reflux in infants, evaluation of treatment by pH monitoring. Eur $\mathcal{F}$
Pediatr 1987;146:504-7.
8 Jolley SG, Johnson DG, Herbst JJ, Pena AR, Garnier RC. An assessment of gastroesophageal reflux in children by extended $\mathrm{pH}$ monitoring of the distal esophagus. Surgery 1978;84:16-22.

9 Jolley SG, Herbst JJ, Johnson DG, Books LS, Matlak ME, Condon VR. Patterns of postcibal gastroesophageal reflux in symptomatic infants. Am $\mathcal{F}$ Surg 1979;138:846-50.

10 Lee M, Davies DP, Chan YF. Prone or supine for preterm babies. Lancet 1988;i:1322.

11 Spoelstra AJG, Srikasibhandha S. Dynamic pressure-volume relationship of the lung and position in healthy neonates. Acta Paediatr Scand 1973;62:176-80.

12 Wagaman MJ, Shutack JG, Moomjian AS, Schwartz JG, Shaffer THE, Fox WW. Improved oxygenation and lung compliance with prone positioning of neonates. $\mathcal{f}$ Pediatr compliance with
1979;94:787-91.

13 Martin RJ, Herrell N, Rubin D, Fanaroff A. Effect of supine and prone positions on arterial oxygen tension in the and prone positions on arterial oxygen tens

14 Dhande VG, Katwinkel J, Darnall RA. Prone position reduces apnea in preterm infants. Pediatr Res 1982;16: $285 \mathrm{~A}$.

15 Anonymous. Cot-death. $\mathrm{Br} \mathrm{Med} \mathcal{F}$ 1971;iv:250-1.

16 Hutchinson AA, Ross KR, Russell G. The effect of posture on ventilation and lung mechanics in preterm and light-fordate infants. Pediatrics 1979;64:429-32.

17 Masterton J, Zucker C, Schulze K. Prone and supine positioning effects on energy expenditure and behaviour of low birth weight neonates. Pediatrics 1987;80:689-92.

18 Anonymous. Prone or supine for preterm babies. Lancet 1988;i:688.

19 Jones DA. Sudden infant death syndrome. $\mathrm{Br}$ Med $\mathrm{f}$ 1989;298:722.

20 Conner AN. The prone position, scoliosis and cot death. $\mathrm{Br}$ Med F 1989;298:1178.

21 Davies DP, Cheng JYC, Lee N. Cot death and prone sleeping position. Br Med f 1989;298:1519.

22 Palmén K. Prevention of congenital dislocation of the hip. Acta Orthop Scand 1984; 208(suppl): 1-107.

23 Tachdian MO. The foot and leg. Pediatric orthopedics. Philadelphia: WB Saunders, 1972: 1445.

24 Auerbach SP. Common foot problems in children. Pediatr Clin North Am 1961;8:225-47.

25 Reisetbauer E, Czermak H. Die Körperlage des Säuglings. Padiatrische Praxis 1972;11:5-14.

26 Brackbill Y, Douthitt TC, West H. Psychophysiological effects in the neonate of the prone versus the supine placement. $\mathcal{f}$ Pediatr 1973;82:82-4.

27 Keitel HG, Cohn R, Harnish D. Diaper rash, self-inflicted excoriations, and crying in full-term newborn infants kept in the prone or supine position. 7 Pediatr 1960;57:884-6.

28 Vaughan VC, Behrman RE, eds. Nelson's textbook of pediatrics. 12th ed. Philadelphia: WB Saunders, 1983.

29 Illingworth RS. Three months colic. Arch Dis Child 1954;29: 165-74.

30 Carpenter RG, Shaddick CW. Role of infection, suffocation and bottle-feeding in cot death. An analysis of some factors in the histories of 110 cases and their controls. British fournal of Preventive and Social Medicine 1965;19:1-7.

31 Froggatt $P$. Epidemiologic aspects of the Northern Ireland study. In: Bergman AB, Beckwith JB, Ray CG, eds. Proceedings of the second international conference on causes of Proceedings of the second international conference on causes of
sudden death in infants. Seattle: University of Washington sudden death in infants

32 Bergman AB, Ray CG, Pomeroy MA, Wahl PW, Beckwith JB. Studies on the suddent infant death syndrome in King County, Washington. III Epidemiology. Pediatrics 1972; 49:860-70.

33 Kahn A, Blum D, Hennart P, et al. A critical comparison of the history of sudden-death infants and infants hospitalised for near-miss for SIDS. Eur 7 Pediatr 1984;143:103-7.

34 Beal SM. Sudden infant death syndrome: epidemiological comparisons between South Australia and communities with a different incidence. Aust Paediatr $\mathcal{F}$ 1986;22(suppl): 13-6.

35 Davies DP. Cot death in Hong Kong: a rare problem? Lancet 1985;ii:1346-9.

36 Nicholl JP, O'Cathain A. Sleeping position and SIDS. Lancet 1988;ii: 106 .

37 Saternus K-S. Plötzlicher Kindstod- eine Folge der Bauchlage? In: Festschrift Professor Leithoff. Heidelberg: Kriminalistik Verlag, 1985:67-81.

38 Tonkin SL. Infant mortality: epidemiology of cot-deaths in Auckland. NZ Med F 1986;99:324-6.

39 Cameron MH, Williams AL. Development and testing of scoring systems for predicting infants with high risk of sudden infant death syndrome in Melbourne. Aust Paediatr f 1986;22(suppl): $37-45$.

40 Jonge GA de, Engelberts AC, Koomen-Liefting AJM, Kostense PJ. Cot death and prone sleeping position in the Netherlands. Br Med F 1989;298:722.

41 Sénécal J, Roussey M, Defawe G, Delahaye M, Piquemal B. Procubitus et mort subite inattendue du nourrisson. Arch Fr Pediatr 1987;44:131-6.

42 Lee NNY, Chan DP, Davies DP, Lau E, Yip DCP. Sudden infant death syndrome in Hong Kong: confirmation of low incidence. Br Med $\mathcal{F} 1989 ; 298: 721$

43 McGlashan ND. Sleeping postion and SIDS. Lancet 1988;ii: 106.

44 Tonkin S. Sudden infant death syndrome: a hypothesis of causation. Pediatrics 1975;55:650-61.

45 Cross KW, Lewis SR. Upper respiratory obstruction and cotdeath. Arch Dis Child 1971;46:211-3.

46 Beckwith JB. The sudden infant death syndrome: a new eckwith JB. The sudden infant
theory. Pediatrics $1975 ; 55: 583-4$. 
47 Simson LR, Brantley RE. Postural asphyxia as a cause of death in sudden infant death syndrome. $f$ Forensic Sci death in sudden

48 Orr WC, Stahl ML, Duke J, et al. Effect of sleep state and position on the incidence of obstructive and central apnea in infants. Pediatrics 1985;75:832-5. 49 Harding R. Nasal obstruction in infancy. Aust Paediatr $\mathcal{F}$

50 Tonkin SL, Partridge J. The pharyngeal effect of partial nasal obstruction. Pediatrics 1979;63:261-71.

51 Emery JL, Thorton JA. Effects of obstruction to respiration in infants, with particular reference to mattresses, pillows, and their coverings. $\mathrm{Br} \mathrm{Med} \mathcal{F}$ 1968;3:209-13.

52 Swift PGF, Emery JL. Clinical observations on response to nasal occlusion in infancy. Arch Dis Child 1973;48:947-51.

53 Gilles FH, Bina $M$, Sotrel A. Infantile atlantooccipital instability. The potential danger of extreme extension. $A m$ f Dis Child 1979;133:30-7.

54 Saternus K-S, Adam G. Der plötzliche Kindstod. Postmortal Wochenschr 1985;110:297-303.

55 Lawson B, Anday E, Guillet R, Wagerle LC, Chance B, Delivoria-Papadopoulos M. Brain oxidative phosphorylation following alteration in head position in preterm and ation following alteration in head position

56 Nelson EAS, Taylor BJ, Weatherall IL. Sleeping position and infant bedding may predispose to hyperthermia and the and infant bedding may predispose to hyperthermia and

57 Matthew OP, Roberts JL, Thach BT. Pharyngeal airway obstruction in preterm infants during mixed and obstructive apnea. F Pediatr 1982;100:964-8.

58 Anonymous. Buikligging van zuigelingen. Ned Tijdschr Geneeskd 1973;117:1823.
59 Swaak AJ. De slaaphouding in de eerste 7 maanden. Tijdschrift voor feugdgezondheidszorg 1983;15:40-2.

60 Baak JPA, Huber J. Incidence of SIDS in The Netherlands. In: Proceedings of the Francis E Camps international symposium on sudden and unexpected deaths in infancy. Toronto: The Canadian Foundation for the Study of Infant
Death, 1974:157-67.

61 Norvenius SG. Sudden infant death syndrome in Sweden in 1973-1977 and 1979. Acta Paediatr Scand 1988;333(suppl): $1-138$.

62 Wennegren G, Milerad J, Lagercrantz H, et al. The epidemiology of sudden infant death syndrome and attacks of lifelessness in Sweden. Acta Paediatr Scand 1987;76: 898-906.

63 Irgens LM, Skjaerven R, Lie RT. Secular trends in sudden infant death syndrome and other causes of post perinatal mortality in Norwegian birth cohorts 1967-1984. Acta Paediatr Scand 1989;78:228-32.

64 Rintahaka PJ, Hirvonen J. The epidemiology of sudden infant death syndrome in Finland in 1969-1980. Forensic Sci Int 1986;30:219-33.

65 Engelberts AC, Kriegsman DMW, de Jonge GA. Cot death and prone sleeping position. $\mathrm{Br}$ Med $\mathcal{F} 1989 ; 298$ :1518-9.

66 Beal S. Sleeping position and sudden infant death syndrome. Med F A ust 1988;149:562.

67 Dam JMC van, Herrewaarden MJC van, Engelberts AC, Jonge GA de. Tijdschrift voor feugdgezondheidszorg 1989;

68 Sprij AJ, Drewes JBJ, Engelberts AC, Jonge GA de. Slaaphouding zuigelingen najaar 1988. Tijdschrift voor feugdgezondheidszorg 1989;21:53-7.

69 Jonge GA de, Engelberts AC. Cot death and sleeping position. Lancet 1989;ii:1149-50. 